\title{
THERMAL CONDUCTIVITY AND MICROSTRUCTURE OF COPPER COATED GRAPHITE COMPOSITE BY SPARK PLASMA SINTERING PROCESS
}

\begin{abstract}
This study focuses on the fabrication of thermal management material for power electronics applications using graphite flake reinforced copper composites. The manufacturing route involved electroless plating of copper in the graphite flake and sintering process are optimized. The microstructures, interface, thermal properties, and relative density of graphite/Cu composites are investigated. The relative density of the composites shows $99.5 \%$ after sintering. Thermal conductivities and coefficients of thermal expansion of this composites were $400-480 \mathrm{Wm}^{-1} \mathrm{~K}^{-1}$ and 8 to $5 \mathrm{ppm} \mathrm{k}^{-1}$, respectively. Obtained graphite nanoplatelets-reinforced composites exhibit excellent thermo-physical properties to meet the heat dispersion and matching requirements of power electronic devices to the packaging materials.
\end{abstract}

Keywords: Metal matrix composites, Thermal conductivity, Thermal expansion, Interfacial bonding, Spark plasma sintering

\section{Introduction}

Thermal management deals with problems arising from heat dissipation, thermal stresses and warping. It is critical in the packaging of power semiconductors and other microelectronic and optoelectronic devices, including microprocessors, highpower RF devices, laser diodes and light-emitting diodes (LEDs). [1-2] Thermal stresses and warpage in electronic components arise primarily from different coefficients of thermal expansion (CTEs). The increasing use of lead-free solders, which have much higher processing temperatures than lead-tin types, exacerbates the problem. Semiconductors and ceramics have CTEs in the range of 2 to $7 \mathrm{ppm} \mathrm{k}^{-1}$. The CTEs of copper, aluminum and glass fiber-reinforced polymer pc boards are much higher. Decades-old traditional low-CTE materials like copper/tungsten $(\mathrm{Cu} / \mathrm{W})$, copper/molybdenum (Cu/Mo), copper-Invar-copper $(\mathrm{Cu} / \mathrm{I} / \mathrm{Cu})$ and copper-molybdenum-copper $(\mathrm{Cu} / \mathrm{Mo} / \mathrm{Cu})$ have high densities and thermal conductivities that are little or no better than that of aluminum.

When aluminum and copper are used for heat dissipation, significant design compromises are typically required, which can significantly reduce cooling efficiency. It is common to use compliant polymeric thermal interface materials (TIMs) to attach high-CTE heatsinks. Low-CTE solders, now under development, will further alleviate the thermal stress problem.

Many investigations have been made on the diamond/metal composites family, which exhibits high performance with TC ranging from $350 \mathrm{Wm}^{-1} \mathrm{~K}^{-1}$ to $700 \mathrm{Wm}^{-1} \mathrm{~K}^{-1}$ [3]. However, the high price and the poor machinability limit their wide application. Recently, the high quality graphite flake with high TC in basal plane, low density and cheap price is receiving increasing attention [4]. Both binary and ternary aluminum based composites containing the Graphite have been investigated and show remarkable thermal properties [5]. The wettability between $\mathrm{Cu}$ and graphite is poor and flakes are tended to lie on the top of each other in the fabricating process. It is anticipated the problem mentioned above could be overcome by coating the Graphite with copper, which has been successfully used in fabricating graphitecopper composites [6]. In addition, the sparking plasma sintering (SPS), which is characterized by a lower sintering temperature, a higher heating rate and the application of the current, has been applied in the development of high performance metal matrix composites [7] the Graphite-copper composites were fabricated using a SPS, which involves coating Graphite with copper, using electroless plating technique. The relative density of the composites up to $99.5 \%$ was achieved and Graphite homogeneous dispersion in composites was obtained.

\section{Experimental}

The graphite (density of $2.231 \mathrm{~g} \cdot \mathrm{cm}^{-3}$, Qingdao Krofmuehl Graphite Co., Ltd.) was used as starting material. Prior to electroless copper plating, the graphite was heat treated at $380^{\circ} \mathrm{C}$ in

\footnotetext{
* DAEGU MECHATRONICS AND MATERIALS INSTITUTE(DMI), 12 HORIM-DONG, DALSEO-GU, DAEGU, REPUBLIC OF KOREA

** DEPARTMENT OF MATERIALS SCIENCE AND METALLURGICAL ENGINEERING, KYUNGPOOK NATIONAL UNIVERSITY(KNU), 1370 SANGYEOK-DONG, BUK-GU, DAEGU, REPUBLIC OF KOREA

\# Corresponding author: ijson@knu.ac.kr, shpark@dmi.re.kr
} 
air for 15 min to remove the surface adhesive, then ultrasonic treated in the acetic acid, copper was deposited on the graphite in a coating bath involving 70wt\% CuSO4_5H2O, 10 wt\% HCHO aqueous solution at $45^{\circ} \mathrm{C}$ under $\mathrm{pH}$ value of 8-11 (adjusted using $\mathrm{NaOH}$ ). The thickness of coating can be controlled by the amount of Graphite in the plating bath. Finally, after rinsed in distilled water several times and dried in vacuum drier (at $60^{\circ} \mathrm{C}$ ). The consolidation of the copper coated graphite was as follows: the coated graphite was loaded into a rectangular graphite die with an inner diameter for $40 * 40 \mathrm{~mm}$ in several batches. Then, the graphite-copper composites were fabricated by spark plasma sintering (SPS-3.20MK-V, DR. SINTER Co., Ltd., Japan) with a sintering pressure of $50 \mathrm{MPa}$ and a sintering temperature of $920^{\circ} \mathrm{C}$. The sintered density was measured by the Archimedes method, and a composite material having a theoretical density of $4.31 \mathrm{~g} \cdot \mathrm{cm}^{-3}$ was successfully prepared. The phases of the products were determined using an x-ray diffraction(X-Pert Pro MRD, PANalytical Philips) and raman spectrometer(Invia Reflex, Renishaw). The observation for interface area was carried out on transmission electron microscopy (JEM-2100F, Jeol). Thermal conductivity (TC) was measured by thermal physical (Netzsch, LFA 457, Germany). Due to the sample size limitation, the TC in perpendicular pressing direction (X-Y plane) was measured. The schematic view of two-dimensional volume of the fabricated composite, indicating the direction along which a given property was measured (parallel or perpendicular to the graphite basal planes).

\section{Results and discussion}

\subsection{Study of phase-identification and composite microstructure}

SEM images were prepared using a steel mold as shown in Figure 1D for graphite powder and copper composite materials. Cross section of the sintered composite powder shows that

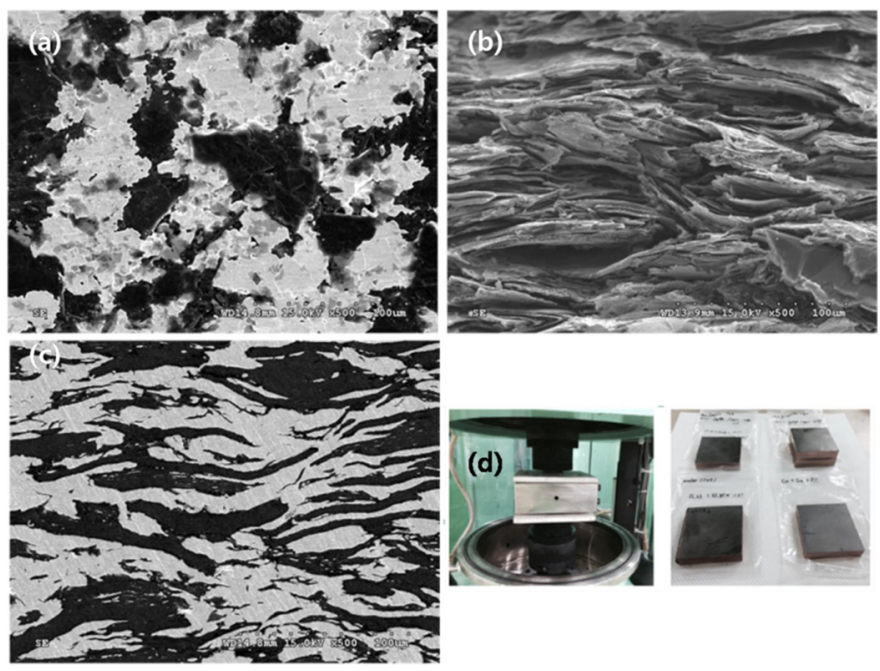

Fig. 1. SEM microstructure of copper-graphite composites and sintered product : (a) Plane image, (b) Fracture image, (c) Cross-sectional image the graphite powder in the copper matrix is laminated and has anisotropy in the mixed phase, as shown in Figure 1b. The plane image of the sintered body, and the cross-sectional image of the sintered body, as shown in Figure 1a,c. The graphite (black gray) are uniformly dispersed in the Cu matrix (light gray), Graphite is basically oriented in the plane perpendicular to the pressing direction. However, some flakes are bent or curled, particularly on the edge, which is relevant to their original morphology.

The significant structural changes occurring during the chemical processing from pristine graphite to Graphite oxide (GO), and then to the reduced GO, are also reflected in their Raman spectra as shown in Figure 2. The Raman spectrum of the pristine graphite, as expected, displays a prominent $\mathrm{G}$ peak as the only feature at $1581 \mathrm{~cm}^{-1}$, corresponding to the firstorder scattering. In the Raman spectrum of GO, the $\mathrm{G}$ band is broadened and shifted to $1594 \mathrm{~cm}^{-1}$. In addition, the D band at $1363 \mathrm{~cm}^{-1}$ becomes prominent, indicating the reduction in size of the in-plane sp2 domains, possibly due to the extensive oxidation at starting composite powders. The Raman spectrum of the reduced GO also contains both G and D bands (at 1584 and $1352 \mathrm{~cm}^{-1}$, respectively); however, with an increased D/G intensity ratio compared to that in GO (at interface Gr. \& Cu) [9].

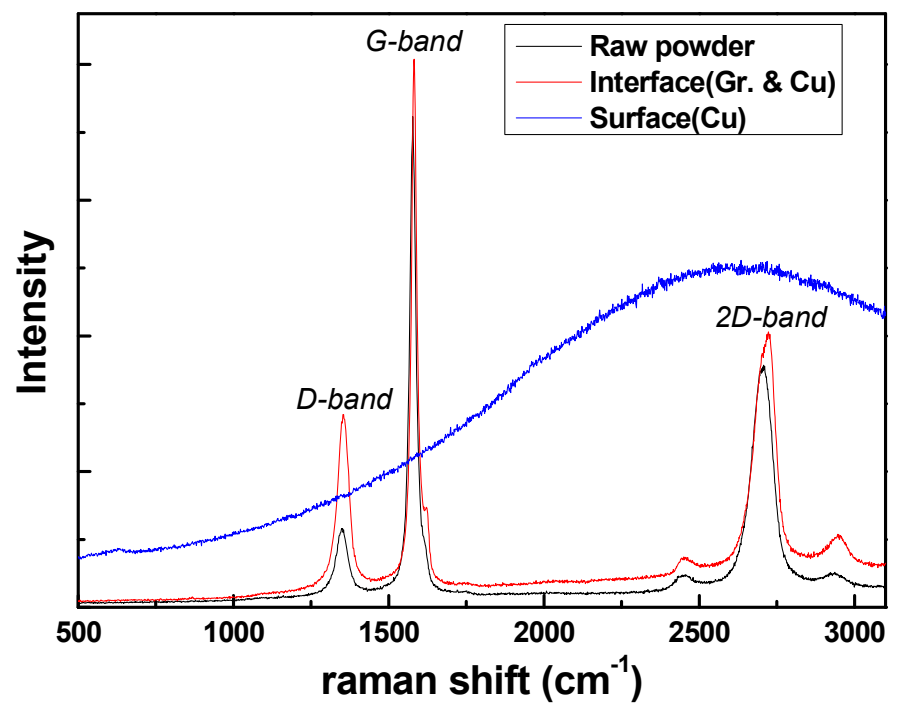

Fig. 2. Comparison of raman spectra of $\mathrm{Cu}$ surface and composites interface

The raman analysis results that the D-band value is relatively high in copper and graphite interface. It investigated the association of GO remains whether and thermal conductivity at the interface. Graphite oxide has a similar layered structure to graphite, but the plane of carbon atoms in graphite oxide is heavily decorated by oxygen-containing groups, in which expand the interlayer distance. The most attractive property of $\mathrm{GO}$ is that it can be (partly) reduced to graphene-like sheets by removing the oxygen-containing groups with the recovery of a conjugated structure.

The EDS image of the interface structure of graphitecopper matrix. Despite the absence of wetting between copper and graphite, the observed interface is quite continuous and no 
obvious gaps have been observed at nanometer resolution. The energy dispersive spectroscopy is used to analyze the elements at the interface region (position $\mathrm{A}, \mathrm{B}$ and $\mathrm{C}$ ), The regions $\mathrm{A}, \mathrm{B}$ and $\mathrm{C}$ correspond to the $\mathrm{Cu}$ matrix, graphite- $\mathrm{Cu}$ interface and graphite as shown in Figure 3a-c.

Oxidation of the copper surface due to the reduction process during SPS sintering is somewhat reduced. The amorphous layer of 5-6 nm observed in the TEM image was confirmed as a laminate of graphite oxide and reduced graphite oxide. The resulting EDS point analysis shows some reduced graphite oxide composition for each location as shown in Figure 4.

\subsection{Thermal conductivity (TC) of graphite-copper composites}

The thermal conductivity of graphite-copper composites. At room temperature indicates the highest $480 \mathrm{w} / \mathrm{m} . \mathrm{K}$ value in the $\mathrm{x}-\mathrm{y}$ direction, as shown in Figure 5. The TC of composites shows an obvious anisotropy. The TC in basal plane is 4-9 times higher than that of in the $\mathrm{z}$-direction. Here, attention is focused on the TC in X-Y plane of the composites. Predictions of TCs in $\mathrm{X}-\mathrm{Y}$ plane are made using the method proposed by Hatta Taya, which assumes that the reinforcements are oriented thin
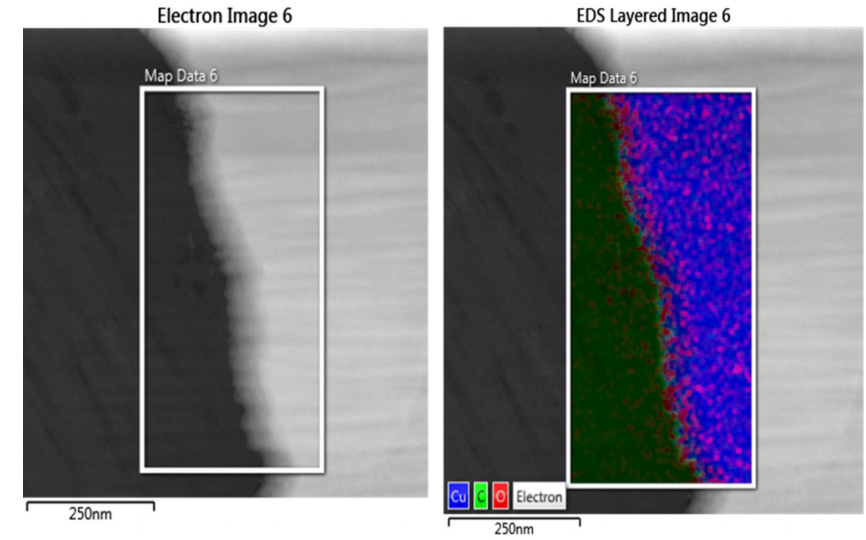

EDS Layered Image 2

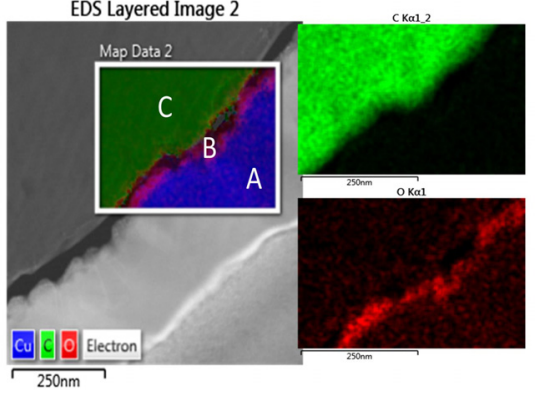

Fig. 3. Enery dispersive spectroscopy(EDS) mapping analysis of composite interface : (a) $\mathrm{Cu}$ rich, (b) interface(Graphite oxide), (c) Graphite rich

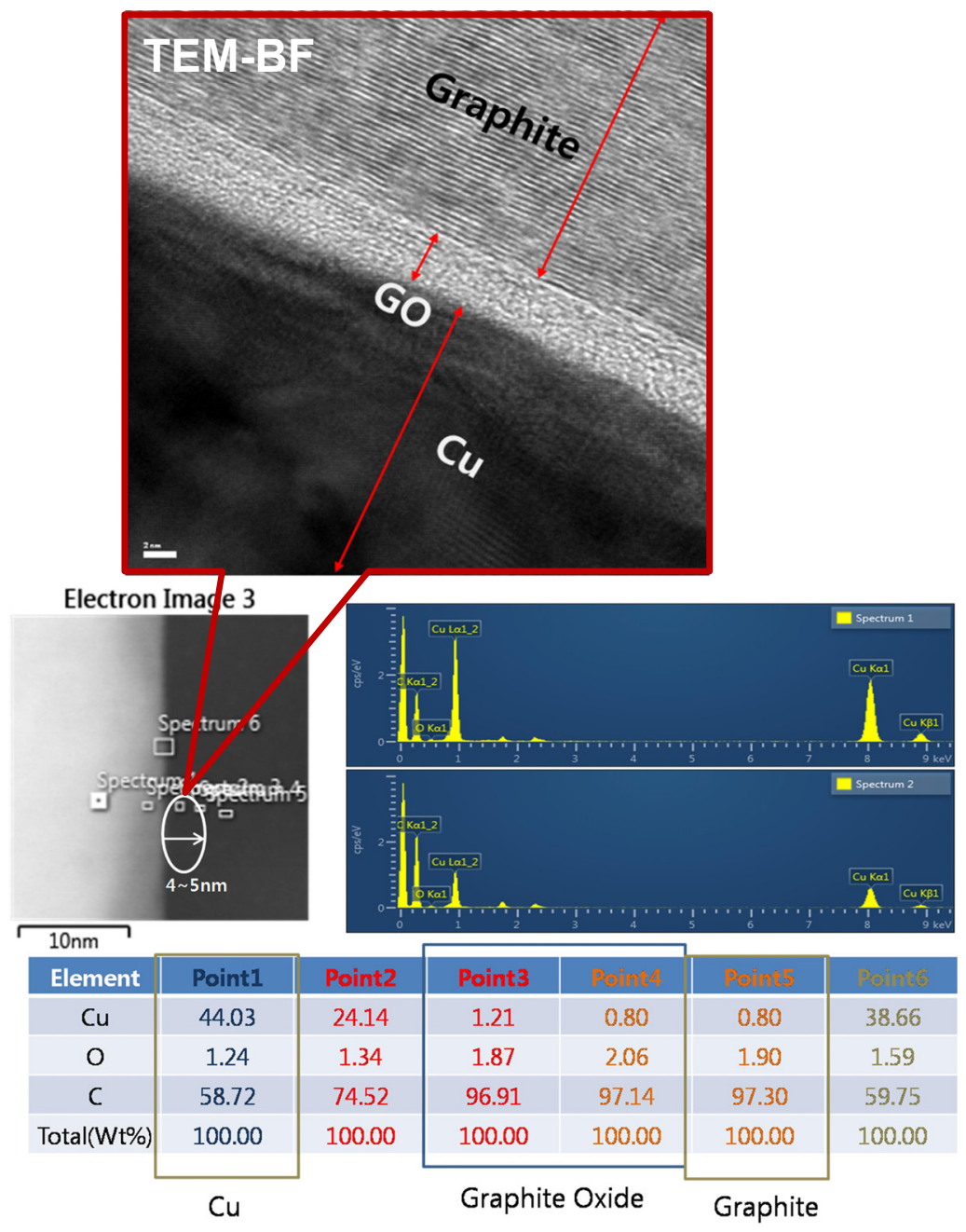

Fig. 4. TEM and EDS results of the multilayer interface of composites 
discs homogenously distributed in the matrix [8]. which has an anisotropic structure, the phonon velocities in basal plane and c-axis direction varies greatly. However, the region of interfacial roughness on a microscopic level may effectively take a weighted-average crystallographic direction for energy propagation across the interface.

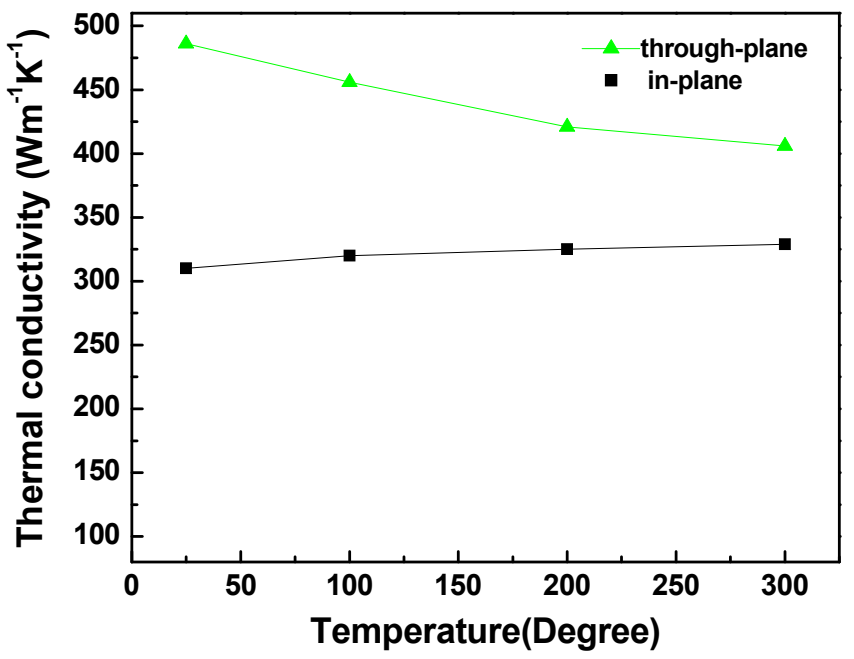

Fig. 5. The thermal conductivity according to the temperature of specimens prepared by through-plane $(X-Z)$, in-plane $(X-Y)$ directions

\section{Conclusions}

In summary, graphite-copper composites were fabricated by using the electroless plating process, followed by spark plasma sintering. The obtained composites containing 44-71 vol.\% of graphite flake have a high relative density over $98.3 \%$. The graphite flake distributed homogeneously in the copper matrix and the interface between graphite flake and copper was continuous and clean. With the increasing of graphite flake, the basal plane TC of composites increases from 400 to $480 \mathrm{Wm}^{-1} \mathrm{~K}^{-1}$ and the CTE decreases from 8.1 to 5.0. The obtained graphite- copper composites exhibit adaptive thermal properties which can be adjusted with the volume ratio of the graphite flake. Given its excellent thermal properties as well as the cheap price and machinability, the graphite-copper composite is an attractive competitor to the electronic packaging materials. In the future, we will investigate the effect of thermal conductivity on the reduction of $\mathrm{GO}$ by analyzing the $\mathrm{C} / \mathrm{O}$ ratio and $\mathrm{SP}_{2}$ bond structure and properties of composites through XPS method.

\section{Acknowledgments}

This research was financially supported by Commercialization of private research projects DMI (2015-25660)

\section{REFERENCES}

[1] S.D. Strand, "Future Technology in the Global Market,"Power Systems World, Oct. 23-27, 2005.

[2] J. Markoff, “Intel’s Big Shift After Hitting Technical Wall,”New York Times, May 17, 2004.

[3] S.B. Ren, X.Y. Shen, C.Y. Guo, N. Liu, J.B. Zang, X.B. He, X.H. Qu, Compos. Sci. Technol. 71, 1550-1555 (2011).

[4] C.-Y. Wen, G.-W. Huang, J. Power Sources 17, 8 132-140 (2008).

[5] R. Prieto, J.M. Molina, J. Narciso, E. Louis, Composites Part A 42, 1970-1977 (2011).

[6] J. Barcena, J. Maudes, J. Coleto, J.L. Baldonedo, J.M. Gomez de Salazar, Compos. Sci. Technol. 68, 1384-1391 (2008).

[6] H. Hiroshi, T. Minoru, Int. J. Eng. Sci. 24, 1159-1172 (1986).

[7] H. Kwon, J. Park, J. Korean Powder Metall. Inst. 23 3, 195-201 (2016).

[8] A.J. Schmidt, K.C. Collins, A.J. Minnich, G. Chen, J. Appl. Phys. 107, 104907 (2010).

[9] S. Stankovich, D.A. Dilin, R.D. Piner, Carbon 45, 1558-1565 (2007). 